\title{
Design of Table Top Electrocoagulation Unit for Remediation of Wastewater from Paper Industry
}

\author{
Table Top Electrocoagulation Unit for Wastewater Treatment
}

\author{
Siddharth Meshram ${ }^{1}$ \\ ${ }^{1}$ Associate Professor, \\ Department of Applied Chemistry, \\ Laxminarayan Institute of Technology, \\ Rashtrasant Tukadoji Maharaj Nagpur University, \\ Nagpur, Maharashtra 440033, India.
}

\author{
Piyush Amrutkar ${ }^{3}$ \\ ${ }^{3}$ Research Student, \\ Department of Chemical Engineering, \\ Laxminarayan Institute of Technology, \\ Rashtrasant Tukadoji Maharaj Nagpur University, \\ Nagpur, Maharashtra-440033, India
}

\author{
Laxmi Yergude ${ }^{2}$ \\ ${ }^{2}$ Department of Chemical Engineering, \\ BIT's Pilani, K.K. Bira Goa, India.
}

\begin{abstract}
The water pollution caused by organic and inorganic compounds is a global problem originated by natural or anthropogenic sources; particularly the effluent generated by paper and pulp industries. This paper highlights the usage of mobile electro coagulation as one of the efficient and inexpensive remedy for treatment of water and wastewater. The effluent source from the paper industries usually have severe pollutant load that may exceed the TSS value $1000 \mathrm{ppm}$, TDS of $5000 \mathrm{ppm}$ and COD up to $20,000 \mathrm{ppm}$ carrying pungent odor and color. The table top design of Electrocoagulation unit for the aforesaid treatment consists of iron/ aluminum as sacrificial anode with rotational facility. Special emphasis has been focused to investigate the optimum operational conditions viz. effect of $\mathrm{pH}$, contact time and selectivity of electrode for maximum removal efficacy. The proposed research work clearly reveals the impact of the gyration of electrodes which facilitates the intimacy between the metal cations with the effluent, results in significant reduction in pollution load. Using the aforesaid mechanism under optimum conditions; color, odor, TSS, TDS and COD removal has been noted up to $95 \%, 100 \%, 95 \%, 49 \%$ and $71 \%$ respectively.
\end{abstract}

Keywords: Coagulation; effluent; electrodes; wastewater.

\section{INTRODUCTION}

At the turn of the last century, it was estimated that about one-sixth of the total world's population are supplied with polluted water. The right of all people to access suitable water supplies must thus be seen as a global challenge, the solution of which is dependent on the formulation and implementation of sustainable water management strategies [1]. In this new era, sustainability is the main factor to encounter the challenges of depletion of our reserves and environmental upsets. Effluents of paper industries contain highly toxic compounds and organic bio-refractory compounds which accounts for high COD, BOD, TDS and TSS along with pungent odor and color [3]. Pulp and Paper industries have been responsible for important technical and socio-economic impacts in a country. They are distinguished contributors of pollutants to the environment in the form of black liquor. Lignin in black liquor contributes to more than $50 \%$ of the total COD load [3.4]. It harms fish, wildlife and contaminates the food chain if poured down a storm drain. Water usage is high in Paper Industries, based on type of paper produced and its cost of processing and supplying. However, it is highest in specialty paper mills and it varies from $370-1220 \mathrm{~m}^{3} / \mathrm{ton}$ of paper $[5,6]$. The global best specific water consumption is $28.66 \mathrm{~m}^{3} /$ ton of paper. This large gap is because of use of conventional manufacturing and treatment technologies and less water management practices by industries. In comparison with international standards Indian Paper industry uses 200\% more water, $10 \%$ more chemicals and about $30 \%$ excess raw material and energy [7]. It has often observed that water is the most misused commodity in the industry. The mini paper mills having capacities below 30 TPD (tones per day) accounts for nearly $20 \%$ of total production in the country. The entire black liquor is discharged as pulp wash water in small mills as it is not economic to go for chemical recovery. Pollution load from small mills is therefore nearly equal to that of big mills.

In recent years, variety of novel processes for efficient and adequate treatment of industrial effluent with relatively low operating costs has been explored due to strict environmental regulations [8,9]. Electrocoagulation process has been attracted a great attention for treatments of industrial wastewater such as pulp and paper mill and rayon pulp mill [10]. Literature reports state that attempts were made to increase the efficiency of the process by making use of punched or oscillating electrodes [11].

\subsection{Description of Technology}

Industrial wastewater is in possession of impurities including colloidal particles and dissolved organic substances. The finely dispersed colloids or suspended solids are usually repelled by their outer layer of negative electrical charges and maintain the colloidal nature until treated by flocculants/coagulants for their removal [12]. This article 
emphasizes on the use of Electrocoagulation technique as a tool to promote the trends of sustainability in the existing industrialized world. The host of very promising techniques based on electrochemical technology is being developed but are not yet to the commercial stage. In essence, an electrocoagulation reactor is an electrochemical cell wherein a sacrificial metal anode, usually aluminum but occasionally iron, is used to dose the polluted water with a coagulating agent [13-18]. Electrocoagulation introduces metal cations in situ rather than via external dosing. It is the electrochemical production of destabilization agents (such as $\mathrm{Al}, \mathrm{Fe}$ ) that brings about neutralization of electric charge for removing pollutant. This process has proven very effective in removing contaminants from water and is characterized by reduced sludge production, no requirement for chemical use and ease of operation [19]. The EC technology offers an alternative usage of metal salts or polymers and poly-electrolyte addition for breaking stable emulsions and suspensions. The technology removes metals, colloidal solids and particles, and soluble inorganic pollutants from aqueous media by introducing highly charged polymeric metal hydrozide species, consuming electrodes that supply ions into the wastewater stream. A conceptual framework of an overall EC process is linked to coagulant generation, pollutant aggregation, and pollutant removal by flotation and settling when it has been applied efficiently to various water and wastewater treatment processes [20].This give similar effect as the addition of metal based salt as a coagulant in a conventional treatment systems. The basis of electrocoagulation is the in-situ formation of a coagulant species that can remove various pollutants from the wastewater being treated.

Electrodes when connected to an external power source, the anode material will electrochemically corrode due to oxidation, while the cathode will be subjected to passivation. The electrodes get consumed slowly with passage of time and hence these electrodes are also called as sacrificial electrodes. Hydrogen gas is liberated at cathode. At commercial scale, the generation of hydrogen can compensate the operational cost [21].

It is important to describe the general electrolytic reactions to understand the fundamental mechanisms of the electrochemical behavior of the system.

When iron is used as anodes, upon oxidation in an electrolytic system, it produces iron hydroxide, $\mathrm{Fe}(\mathrm{OH})_{\mathrm{n}}$

Where $\mathrm{n}=2$. The main reactions that occur at the electrodes are shown in (Eq.1): [22]

$$
4 \mathrm{Fe}(\mathrm{x})+10 \mathrm{H}_{2} \mathrm{O}+\mathrm{O}_{2} \stackrel{\text { When n = 2 }}{\stackrel{\text { 列 }}{\longrightarrow}} \mathrm{Fe}(\mathrm{OH})_{3(\mathrm{~s})}+4 \mathrm{H}_{2}
$$

However when $\mathrm{n}=3$, it gives following reaction (Eq.2):

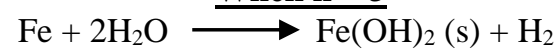

In case when Aluminum is used as an anode, the reactions will proceed in the following manner (Eq.3):

$$
\begin{aligned}
& 2 \mathrm{Al}_{(s)}+6 \mathrm{H}_{2} \mathrm{O}+2 \mathrm{HO}_{(a q)}^{-} \longrightarrow \\
& 3 \mathrm{H}_{2(g)}
\end{aligned}
$$

Similarly, ferric ions generated by electro-chemical oxidation of iron electrode may form monomeric ions, and polymeric hydroxyl complexes, namely: $\mathrm{Fe}\left(\mathrm{H}_{2} \mathrm{O}\right)_{6}{ }^{3+}$,
$\mathrm{Fe}\left(\mathrm{H}_{2} \mathrm{O}\right)_{5}(\mathrm{OH})_{2}{ }^{+}, \mathrm{Fe}\left(\mathrm{H}_{2} \mathrm{O}\right)_{4}(\mathrm{OH})_{2}{ }^{+}, \mathrm{Fe}_{2}\left(\mathrm{H}_{2} \mathrm{O}\right)_{8}(\mathrm{OH})_{2}{ }^{4+}$ and $\mathrm{Fe}_{2}\left(\mathrm{H}_{2} \mathrm{O}\right)_{6}(\mathrm{OH})_{4}{ }^{4+}$ depending on the $\mathrm{pH}$ of the aqueous medium [23-25]

The schematic route of wastewater sources and its recycling is depicted in Fig.1.

\section{MATERIALS AND METHODOLOGY}

\subsection{Procurement of original wastewater sample}

The original wastewater sample was obtained from the paper industry from nearby areas of Maharashtra region. The wastewater sample was dark in color containing large amount of organic solids.

\subsection{Chemical analysis of wastewater}

The wastewater sample was analyzed initially for different parameters such as color, $\mathrm{pH}$, TSS, TDS and COD. The chemical and physical parameters of the wastewater sample analyzed are given in Table 1 .

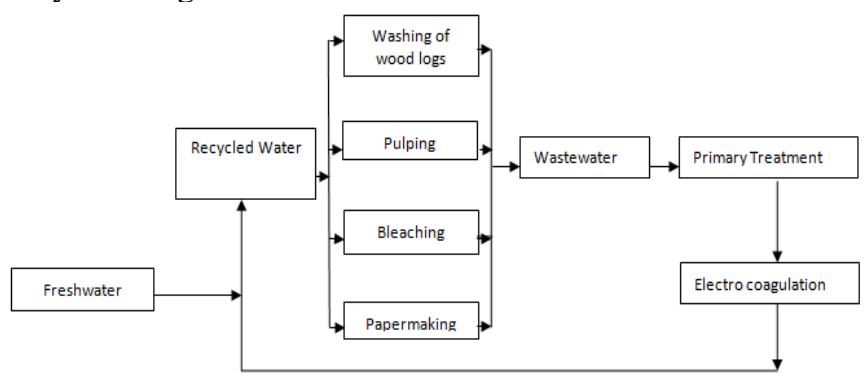

Fig. 1 Sources of Wastewater and its recycling

Table 1. Chemical and Physical parameters of the

\begin{tabular}{|l|l|}
\hline Parameters & Values \\
\hline $\mathrm{pH}$ & 8.6 \\
\hline Color & Coke \\
\hline Total Suspended Solids (ppm) & 650 \\
\hline Total Dissolved Solids (ppm) & 23850 \\
\hline Chemical Oxygen Demand (ppm) & 2400 \\
\hline
\end{tabular}

\subsection{Design and Fabrication of Electrocoagulation Unit}

In its simplest form, an electro coagulating reactor consists of an electrolytic cell with two sacrificial electrodes having dimension of $13 \mathrm{~mm} \times 80 \mathrm{~mm}$. The distance between two electrodes kept is $1.5 \mathrm{~cm}$ whereas; the total surface area of each electrode is $1.04 \times 10^{-3} \mathrm{~m}^{2}$. These are attached to the wooden strip which rotates, facilitating the electrodes to move with the help of external power source. The external DC power supply provides voltage of $12 \mathrm{~V}(0.12 \mathrm{~A})$. The rotating speed of electrodes can be controlled with suitable means on the wooden strip. A schematic presentation of an EC cell with pair of mobile electrodes is given in Fig.2.

However, the circuit diagram outlines the power supply to the electrodes using 12 V D.C motor is displayed in Figure 3. 


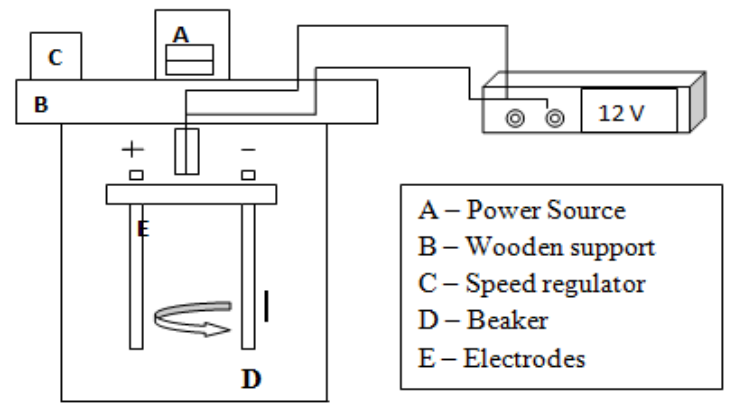

Fig.2. Electrocoagulation set up with mobile electrodes

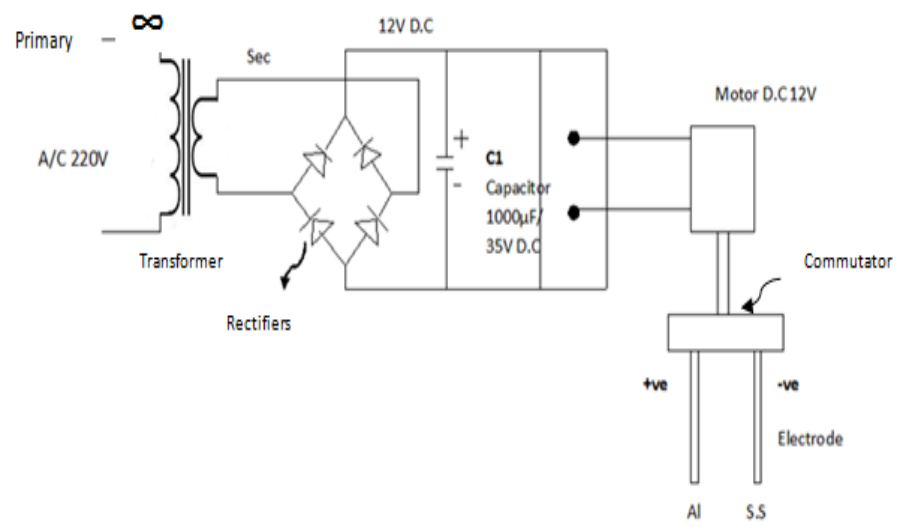

Fig.3 D.C Circuit showing current supply

\section{EXPERIMENTAL WORKS}

3.1. Electrocoagulation route for treatment of wastewater

The waste water sample of about $1.5 \mathrm{~L}$ is subjected for Electrocoagulation. Here the sample was allowed to undergo the process for regular time intervals ranging from $0-3 \mathrm{~h}$ keeping current density, $\mathrm{pH}$ and rpm constant. Aluminum and Iron were selected as suitable electrodes arranged in parallel for the EC process. The aluminum and iron electrodes has been used as sacrificing anodes in electrolytic oxidation for the production of $\mathrm{Al}(\mathrm{OH})_{3} \cdot \mathrm{XH}_{2} \mathrm{O}$ and $\mathrm{Fe}(\mathrm{OH})_{3} \cdot \mathrm{XH}_{2} \mathrm{O}$ respectively in different batch experiments whereas stainless steel is used as cathode in both the cases. When connected to an external power source, the anode material will electrochemically corrode due to oxidation, while the cathode will be subjected to passivation. This study was also partially focused to compare the effectiveness of Aluminum ( $\mathrm{Al})$ and Iron $(\mathrm{Fe})$ as electrodes to reduce the polluting nature of Paper Mill Effluent and simultaneous hydrogen production during Electrocoagulation (EC). The operative parameters along with the necessary conditions are displayed in Table 2 .

3.2. Optimization of Reaction Parameters

The parameters considered in this study includes color, odour, TSS, COD and TDS. Although the color and odour of the wastewater sample after Electrocoagulation treatment was disappeared completely, however it was noticed that the COD, TDS and the TSS content of the wastewater sample were the matter of concern. Thus, the process further optimized considering these parameters only.

\section{RESULTS AND DISCUSSION}

The influence of various parameters such as $\mathrm{pH}$, time and current density on the removal efficiency of the wastewater sample was examined. The photographic image of effluent with pre and post electrocoagulation has been recorded in Fig.4. The difference in the colour of the effluent after electrocoagulation is clearly revealing the significance of the process.

Table 2. Optimum Parameters for Electrocoagulation

\begin{tabular}{|l|l|}
\hline Operational Parameters & Conditions/Values \\
\hline Electrode Material & Aluminum / Iron and Stainless Steel \\
\hline Area of Electrode & $13 \mathrm{~mm} \times 80 \mathrm{~mm}$ each \\
\hline RPM of electrodes & $42-45 \mathrm{rpm}$ \\
\hline Arrangement & Parallel \\
\hline Distance between two electrodes & $1.5 \mathrm{~cm}$ \\
\hline Voltage & $12 \mathrm{~V}$ \\
\hline Current Density & $41.95 \mathrm{~A} / \mathrm{m}^{2}$ \\
\hline
\end{tabular}

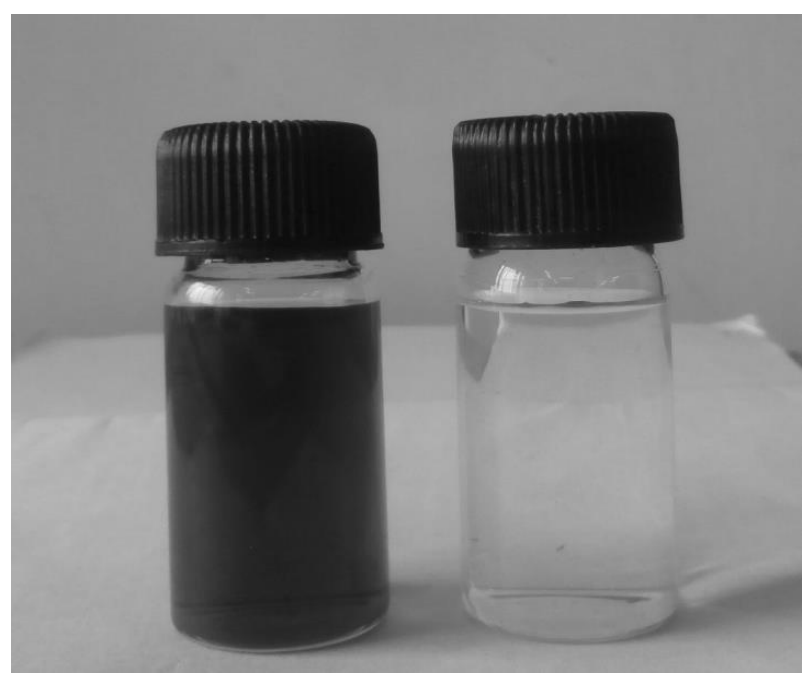

Fig.4. Effluent with pre (left) and post (right) Electrocoagulation treatment

4.1 Effect of $p H$

It has been noticed that the $\mathrm{pH}$ is an important parameter influencing the electrochemical process. The initial $\mathrm{pH}$ of the generated effluent was approximately 10 , which has been lowered by adding dilute $\mathrm{HCl}$. The performance of EC process on wastewater was studied for the initial $\mathrm{pH}$ ranging from 5.0 to 10 for fixed voltage and rpm of electrodes for $1 \mathrm{~h}$. The maximum \% removal was achieved in the $\mathrm{pH}$ range of 7.0 to 8.0 as revealed in Fig.5.

\subsection{Effect of operating time}

It was noticed that the operating time also plays significant role in removal efficacy for TDS, TSS, COD and color as well. The reaction time was optimized keeping other parameters constant i.e. voltage, $\mathrm{pH}$, and $\mathrm{rpm}$. Here the removal of aforesaid parameters was investigated as a function of time represented in Fig. 6 and Fig. 7 respectively. It was 


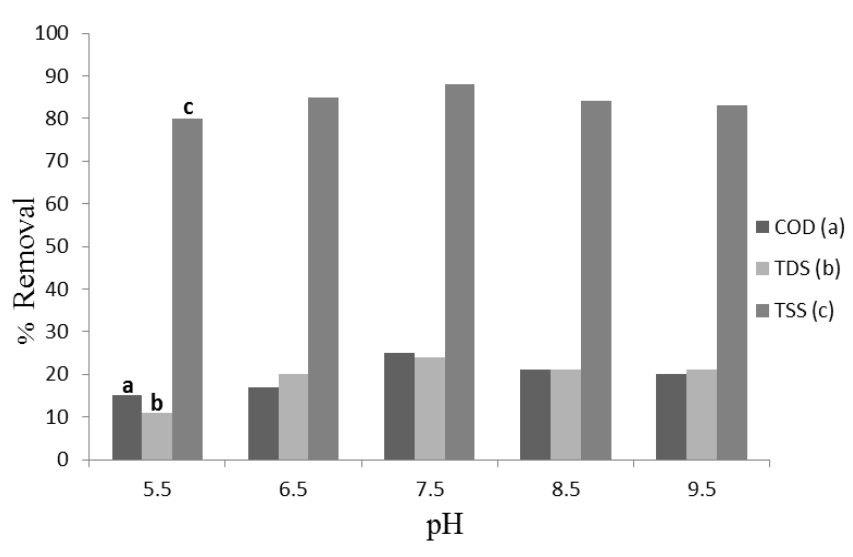

Fig.5. Removal efficiency of COD, TDS and TSS against $\mathrm{pH}$

deduced that the increase in time yielded a substantial improvement in removal efficiencies. The maximum percent removal was noted at $2.5 \mathrm{~h}$ keeping the rpm constant. However, if the operating time is increased beyond it; the TDS value of the wastewater sample was observed to be increasing rather than decreasing. This anomalous behavior may be due to the formation of few water soluble complexes after coagulation which may raise the TDS value.

\subsection{Effect of Electrodes Combination}

During the experimental work it was observed that the electrode used in the combination with Stainless Steel as a cathode, is showing remarkable effect on the removal efficiency. In this experiment we have used two electrodes individually as an anode in combination with Stainless Steel which was used as cathode. The removal efficiency varies in both the cases. Here, the combination of SS (cathode) with aluminum as anode proves to give higher efficiency as compared with iron. It was further noticed that, during EC process using Iron (anode) for both the voltages, it imparts a greenish shade in the wastewater, which also affects the TDS value depicted in Fig.8.

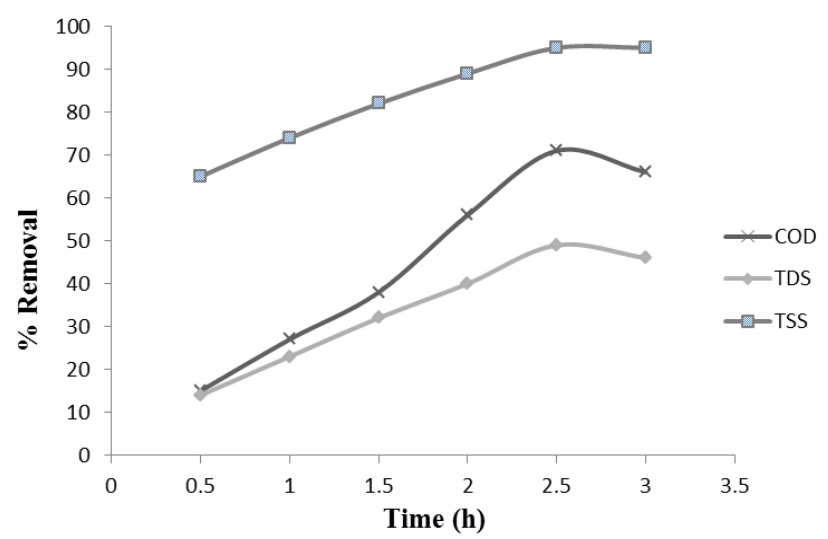

Fig.6. COD, TDS and TSS removal efficiency of Wastewater Sample with $\mathrm{Al}$ (Anode)

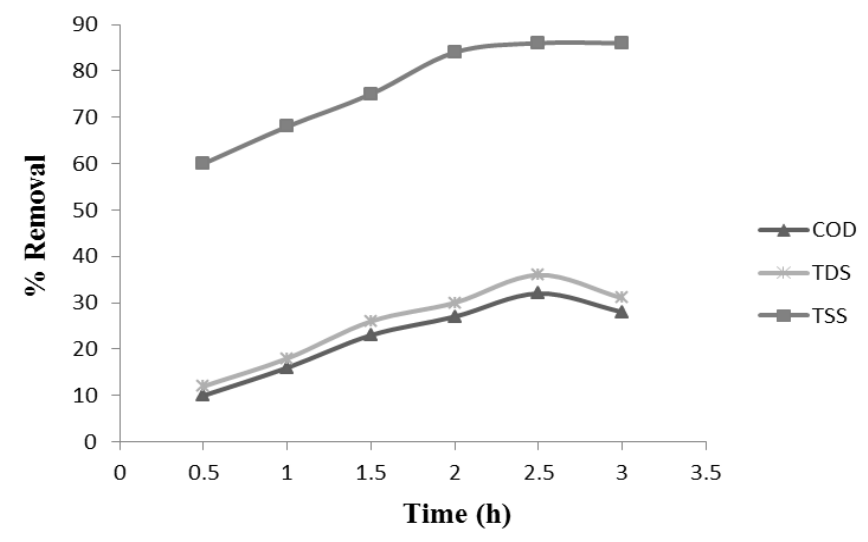

Fig.7. COD, TDS and TSS removal efficiency of Wastewater Sample with Iron (Anode)

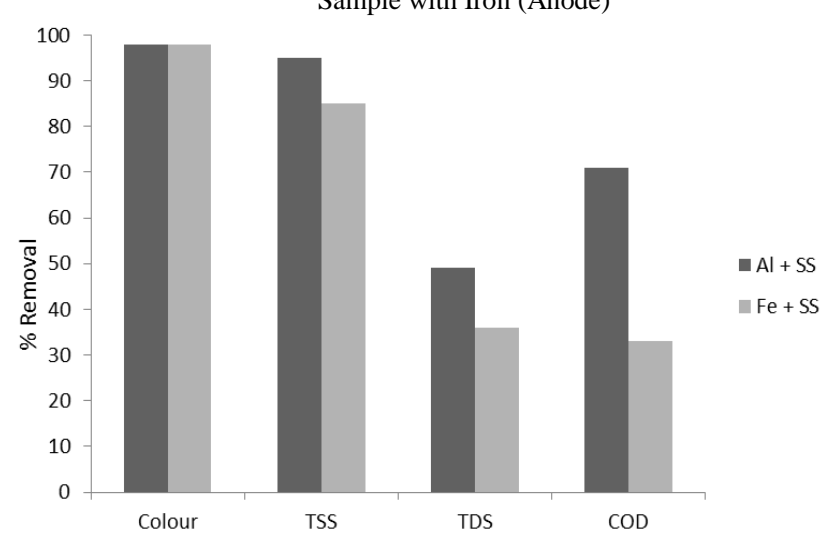

Fig.8. Effect of Combination of Electrodes on removal efficiency

\section{CONCLUSIONS}

The efficiency of the Electro-coagulation treatment for the effluent from paper industry has been considered in this case study. Then effluent was treated having electro-coagulation method using iron and aluminum metal as a sacrificial anode. The mobile phase of the electrodes during the electrocoagulation makes the batch model innovative. It was observed that the agitation provokes intimate contact between the surface of electrodes and the pollutant ions present in wastewater, results in higher coagulation without any electrolyte salt. The results obtained during these studies were substantially encouraging. The removal efficiency of electrocoagulation technique using Aluminum electrode has been observed to be a better option as compared to an Iron electrode. However, the encouraging results obtained are pertaining to the dimensions of electrodes as mentioned in the earlier section of paper. It can't be denied that the results would vary to a great extent with the dimensions of electrodes. The steps involved in the overall process are quite simple and non-tedious with high efficiency towards the remediation of effluent from paper and pulp industry.

\section{ACKNOWLEDGEMENT}

The author sincerely expresses gratitude towards the support extended by Prof. R.B.Mankar Director, Laxminarayan Institute of Technology for his constant encouragement. The help and cooperation rendered by Prof.D.C.Anjikar, Head, Department of Paper and Pulp Technology, L.I.T. is greatly acknowledged. 


\section{REFERENCES}

[1] P. Holt, G. Barton, C. Mitchell, "The future for electrocoagulation as a localised water treatment technology" Chemosphere, vol 59, pp 355367 April-2005.

[2] J. Rintala and J. Puhakka, "Anaerobic Treatment in pilp-and paper mill waste management: A Review” Bioresour. Technol, vol 47, pp 1-18, 1994.

[3] R. Jain, A. Gupta, R. Mathur, A. Kulkarni, TAPPI 2001 Pulping Conference. vol 41, p. 1292, 2001.

[4] Abdurrahman A., "Treatment of paint manufacturing wastewater by electrocoagulation," Desalination, vol 285, pp 91-99, January 2012.

[5] Subramanyam, P.V.R., J. Indian Assoc. Environ. Manage., vol 17, p.79, 1990.

[6] H. Worster, M. Pudek, Alkaline Pulping Conference Atlanta, Ga, pp 22-24, 1973.

[7] R. Sharma, S. Kumar, C. Sharma, IPPTA J. 23, vol 4, p. 155, 2011.

[8] O. Sahu, B. Mazumdar, K. Chaudhari, "Electrochemical treatment of sugar industry wastewater: process optimization by response surface methodology," Int. J. Env. Sci. Technol. vol 16, may 2018.

[9] Y. Yavuz, U. Ogutveren. "Treatment of Industrial estate wastewater by the application of electrocoagulation process using iron electrodes," J. Env. Manag., vol 207, pp 151-158, 2018.

[10] M. Ugurlu, A. Gurses, C. Dogar, M. Yalcin, "The removal of lignin and phenol from paper mill effluents by electrocoagulation", J. Environ. Manag., vol 87, pp 420-428, 2008

[11] Paul J. Panikulam, Nael Yasri, Edward P.L. Roberts, "Electrocoagulation using an oscillating anode for kaolin removal." J. Environ. Chem. Engg., 2018.

[12] E. Ali, Z. Yaakob, "Electrocoagulation for treatment of Industrial Effluents and Hydrogen Production", Electrolysis, In Tech, 2012.

[13] N. Barkley , C. Farrell, T. Gardner, "Alternating current electrocoagulation for superfund site remediation" Air Waste, vol 43, p.784, 1993.

[14] P. K. Holt, PhD thesis, Faculty of Engineering, The University of Sydney (2003)

[15] N. Mameri, A. Yeddou, H. Lounici, D. Belhocine, H. Grib, B. Bariou, "Defluoridation of septentrional Sahara water of north Africa by electrocoagulation process using bipolar aluminium electrodes," Water Res. vol 32, p. 16041998.

[16] M. Matteson, R. Dobson, R. Glenn, N. Kukunoor, W. Waits, E Clayfield, "Electrocoagulation and separation of aqueous suspensions of ultrafine particles" Colloids Surf., vol 104, p. 1011995.

[17] M. Pouet, A. Grasmick, "Urban wastewater treatment by electrocoagulation and flotation," Water Sci. Technol., vol 31, p. 275 1995.

[18] M. Mohammad, Sivakumar, Journal of Environmental Management, vol 90, 1663 (2009)

[19] K. Rajeshwar, J. Ibanez, In: Environmental electrochemistry: fundamentals and applications in pollution abatement., M. Tarr (Ed), Academic USA Press, p. $720,1997$.

[20] M Nasution, Z. Yaakob, E. Ali, S. Tasirin, S. Abdullah, "Electrocoagulation of Palm Oil Mill Effluent as Wastewater Treatment and Hydrogen Production Using Electrode Aluminum", J. Environ. Quality, vol 40, p. 1332, 2011.

[21] K. W. Lafi, Environment, Devices, Systems, Communications and Computers, 61 (2011)

[22] N. Daneshvar, A. Oladegaragoze, N. Djafrzadeh, "Decolorization of basic dye solutions by electrocoagulation: An investigation of the effect of operational parameters" J. Hazard. Mater. B, vol 129, p. 116, 2006.

[23] M. Mollah, P. Morkovsky, J. A. Gomes, M. Kesmez, J. Parga, D. L. Cocke, "Fundamentals, present and future perspectives of electrocoagulation.” J. Hazard. Mater. B, vol 114, p. 199, 2004.

[24] M. Ugurlu, A. Gurses, C. Dogar, M. Yalc, "The removal of lignin and phenol from paper mill effluents by electrocoagulation," J. Environ. Manage. vol 87, pp. 420-428, 2008.

[25] S. Mahesh, B. Prasad, I. Mall, L. Mishra, "Electrochemical Degradation of Pulp and Paper Mill Wastewater. Part 1. COD and Color Removal” Ind. Eng. Chem. Res., vol 45, p. 2830, 2006. 